\title{
Analysis of the complex rheological properties of highly concentrated proteins with a closed cavity rheometer
}

https://doi.org/10.1515/arh-2020-0107

Received Aug 27, 2019; accepted Jun 23, 2020

Abstract: Highly concentrated biopolymers are used in food extrusion processing. It is well known that rheological properties of biopolymers influence considerably both process conditions and product properties. Therefore, characterization of rheological properties under extrusionrelevant conditions is crucial to process and product design. Since conventional rheological methods are still lacking for this purpose, a novel approach is presented. A closed cavity rheometer known in the rubber industry was used to systematically characterize a highly concentrated soy protein, a very relevant protein in extruded meat analogues. Rheological properties were first determined and discussed in the linear viscoelastic range (SAOS). Rheological analysis was then carried out in the non-linear viscoelastic range (LAOS), as high deformations in extrusion demand for measurements at process-relevant high strains. The protein showed gel behavior in the linear range, while liquid behavior was observed in the nonlinear range. An expected increase in elasticity through addition of methylcellulose was detected. The measurements in the non-linear range reveal significant changes of material behavior with increasing strain. As another tool for rheological characterization, a stress relaxation test was carried out which confirmed the increase of elastic behavior after methylcellulose addition.

Keywords: Highly concentrated protein, viscoelasticity, extrusion, closed cavity rheometer, large amplitude oscillatory shear (LAOS)

\footnotetext{
^Corresponding Author: M. Azad Emin: Institute of Process Engineering in Life Sciences, Chair of Food Process Engineering, Karlsruhe Institute of Technology, Karlsruhe, Germany; Email: azad.emin@kit.edu; Tel: +49 (0)721 608-48311, Fax: +49 (0)721 608-45967

Patrick Wittek, Nicole Zeiler, Heike P. Karbstein: Institute of Process Engineering in Life Sciences, Chair of Food Process Engineering, Karlsruhe Institute of Technology, Karlsruhe, Germany
}

\section{Introduction}

Extrusion processing is used to produce a wide variety of food products, such as pasta, cereals or meat analogues. In the extruder, highly concentrated biopolymers, such as polysaccharides or proteins, are plasticized, mixed, heated, sheared and pushed through a die to achieve the desired product properties and functionalities [1-3]. During this process, the biopolymers are subject to temperatures of up to $200^{\circ} \mathrm{C}$ and shear rates of up to $5000 \mathrm{~s}^{-1}$ [4].

It is well known that rheological properties play a crucial role in the process. The shear stresses generated by screw rotation are influenced by local viscosity and are responsible for physical and chemical changes, such as dispersive mixing and molecular fragmentation $[5,6]$. During the extrusion of foams (e.g., ready-to-eat cereals), structuring in the extruder die due to expansion is additionally influenced by the elasticity of the material [7-10]. In the case of protein extrusion to produce meat analogues, the flow characteristics in the die section are expected to have a large impact on the structuring of these materials, which again are a strong function of the rheological properties [11-14].

Knowledge of the rheological properties thus helps understand the process and control the product properties $[1,15]$. Accurate rheological data input is also indispensable for analysis of the flow characteristics using numerical methods (CFD) [16-19].

However, characterization of extrusion-relevant rheological properties of biopolymers remains challenging. Rheological methods must cope with very high torque due to the high matrix viscosity and water loss due to evaporation when measurements are carried out at extrusionrelevant temperatures $\left(>100^{\circ} \mathrm{C}\right)$. Many biopolymers, especially native proteins, are highly reactive, which also makes measurements challenging at elevated temperatures. Moreover, highly concentrated biopolymers possess complex rheological properties, as a result there is a need to analyze not only viscous, but also elastic properties. Additionally, the biopolymers experience low to very large de- 
formations in extrusion processing depending on the conditions (e.g., screw speed and geometry) and location of the material (i.e., screw section versus die section). Accordingly, rheological measurements in both the linear and the non-linear viscoelastic range are necessary to gain a better understanding of the rheological behavior of biopolymers during extrusion processing.

Despite these challenges, there is vast amount of research dealing with rheological measurements of highly concentrated biopolymers. Most of them focus on using conventional rotatory plate-plate or plate-cone rheometry. The material is fixed between the two plates, of which one is moving, either in continuous or oscillatory rotational manner, and the resulting material response is determined. This method has been used extensively for the investigation of bread and gluten doughs [20-28]. Most of the work was performed at ambient temperatures (around $25^{\circ} \mathrm{C}$ ), while investigating both viscous and elastic properties in the linear viscoelastic range. More recently, analysis was carried out in the non-linear range $[29,30]$, which is more relevant to processes where high deformations take place. Besides bread and gluten doughs, conventional rotatory rheometers have also been used for predicting the rheological behavior of soy-based dough (either soy flours or soy protein isolates) in extrusion processing [31-33].

With these rotatory rheometers, measurements at temperatures relevant to extrusion remain challenging due to water loss. Below $100^{\circ} \mathrm{C}$, this can be prevented by application of water-impermeable materials, such as silicone oil, on the free surfaces. Above $100^{\circ} \mathrm{C}$, pressurized vessels have to be used to prevent water evaporation [21].

Furthermore, wall slip remains an issue for these materials due to the low normal forces applied by the plates to the material. This can be prevented by gluing the material to the device surface [26] or by application of a rugged surface in the form of either a sand paper underlay [27] or a rugged rheometer surface. For highly concentrated biopolymers (with a very low water content), however, the problem remains, as these biopolymers are initially in powder form and normal forces of the plates are needed to plasticize them at elevated temperatures.

Another major group of studies was performed using pressure-driven capillary rheometers. The term "capillary" originally referred to rheometers of small diameter, while "tube rheometer" was used for viscometers of higher diameter $(6-10 \mathrm{~mm})$ [34]. Hereinafter, all types of pressuredriven rheometers will be referred to as capillary rheometers.

In a capillary rheometer, flow is produced in the capillary through the application of a pressure difference [34, 35]. The apparent viscosity can then be calculated from the volume flow, pressure difference, and geometry parameters of the capillary.

Such rheometers were used extensively in extrusionrelated research, either offline or inline, as they allow for measurements of highly viscous materials at elevated temperatures and pressure without water loss. For example, highly concentrated soy protein isolate was studied using offline capillary rheometers [36-41]. Still, the problems associated with the high reactivity of biopolymers under these conditions must be considered. To obtain a flowable (plasticized) material, biopolymers have to be mixed with water, then heated, and eventually sheared (especially starchy matrices) to produce a homogeneous dough. Shearing can be achieved by a rotating piston, demonstrated, for example, in the "Rheoplast" device [42]. However, the additional amount of time spent in the reservoir of the capillary rheometer must be considered, as even the shortest treatment times at elevated temperatures may dramatically change the rheological behavior of the biopolymers. For instance, viscosity of wheat proteins may double within $30 \mathrm{~s}$ at $140^{\circ} \mathrm{C}$ [43].

This problem can be solved to a certain degree by attaching a capillary or slit die to the extruder exit, which results in a so-called inline capillary rheometer [44]. Here, the material is characterized directly in the extrusion process. These inline rheometers were used extensively for studying protein-based extrusion [36, 45-51] and starchbased extrusion [52-58].

But reactivity remains an issue: Depending on the geometry, it might take up 30 seconds to pass the capillary device, thus leading to changes in the rheological properties along the die. Especially in highly reactive protein extrusion, polymerization was found to occur after the die section [14], i.e., in the inline rheometer between two pressure sensors, and to influence the accuracy and reliability of results.

Moreover, several assumptions have to be applied in the use of capillary rheometers, such as Newtonian material behavior and no-slip conditions. Highly concentrated biopolymer materials are non-Newtonian, however, and require the Weißenberg-Rabinowitsch correction to obtain true shear rates [35]. To correct end effects that occur in the flow close to the capillary inlet, Bagley corrections have to be applied [59]. Occurrence of wall slip is accounted for by applying a Mooney correction [60].

While the investigation of elastic properties remains challenging, capillary rheometers are very well suited to determining viscous properties of materials not prone to any significant structural changes during measurements.

Among others, the closed cavity rheometer (CCR) is an alternative method for characterizing highly concen- 
trated biopolymers under extrusion-relevant conditions. The CCR is well-known in the rubber industry (as Rubber Process Analyzer), but has hardly been used for food biopolymers so far [61-63]. This device was compared thoroughly with other, more conventional dynamic rheometers and found to give good agreement in the rheological measurements [62].

The CCR combines a closed cavity with high-torque oscillatory measurements at very high strains for extended analysis in the non-linear range [63]. Grooved dies prevent wall slip of the material, while water evaporation is prevented by the pressurized closed cavity. Normal forces acting on the material facilitate plasticization of biopolymers and allow physically meaningful measurements. The material can be heated and cooled rather quickly; the probe amount is less than $10 \mathrm{ml} / 8 \mathrm{~g}$.

Pommet et al. [64] performed one of the first studies using a CCR for food biopolymers and investigated the aggregation/degradation behavior of wheat gluten/glycerol blends at elevated temperature under shear conditions. Further studies by our research group [43, 65-71] confirmed the applicability of this rheometer to study the reaction behavior of various protein and proteinpolysaccharide systems under defined extrusion-like conditions. To the best of our knowledge, however, the potentials of this rheometer in characterizing the complex rheological behavior of highly concentrated biopolymers have not yet been reported.

The aim of this paper therefore is to obtain an extensive rheological characterization of a highly concentrated model biopolymer under extrusion-relevant conditions. In particular, information is to be gained on viscous and elastic properties in both the linear and non-linear range, as there is a growing demand for such measurements to improve the understanding of the structuring of biopolymers during extrusion processing.

As a model biopolymer, soy protein was chosen, which has been used in extruded meat analogues since the 1960s [72] and is still the most important protein for that purpose. The proteins from soybeans are classified into four groups, differentiated by their sedimentation constant: $2 \mathrm{~S}, 7 \mathrm{~S}, 11 \mathrm{~S}$ and $15 \mathrm{~S}$ [73]. The two major protein fractions are the storage proteins from the $7 \mathrm{~S}$ (conglycinin) and $11 \mathrm{~S}$ (glycinin) groups. Their molecular weight ranges from 180 to $350 \mathrm{kDa}$ in the native state. In the process of extracting proteins from soy beans to produce soy protein isolate $(>90 \%$ protein content), several steps are performed consecutively: crushing of soy beans, extraction of oil using hexane, addition of alcohol and an acidic precipitation step [74]. It has been shown that these processing steps can heavily influence the protein structure, leading to loss of the protein's native state [73] and therefore their reactivity.

The protein is investigated at $51.7 \%$ moisture content, which corresponds to typical water contents of highmoisture extrusion for producing meat analogues.

As the focus also lies on the characterization of elastic properties, a highly elastic biopolymer will be added (methylcellulose), to find out whether the device is capable of determining expected changes in elastic material properties. Methylcellulose is widely used in the food industry as a binding and thickening agent, e.g., in current formulations for vegan burger patties [75], due to its ability to form thermoreversible gels at temperatures above $52^{\circ} \mathrm{C}$ [76].

First, the linear and non-linear ranges of the material are determined with strain sweeps. Second, rheological properties are investigated in the linear range to obtain time-dependent viscoelastic behavior data. As a third step, rheological properties are analyzed in the process-relevant non-linear range by means of large amplitude oscillatory shear measurements and analysis (LAOS). These types of measurements have already been applied to many different (food) material systems [29, 77-79]; for details, the authors refer to the work of Hyun et al. [80]. Finally, as a fourth step, stress relaxation tests are carried out to obtain additional information on the viscoelastic behavior of the material.

\section{Experimental Procedures}

\subsection{Material}

Commercial soy protein isolate at 3.5\% moisture content (w/w) was purchased from Solae (St. Louis, Missouri, USA). Throughout the paper it will be referred to as "soy protein". According to the manufacturer, it's protein content was $\min .90 .0 \%(\mathrm{w} / \mathrm{w})$. Methylcellulose at 7.0\% moisture content was purchased from Carl Roth (Karlsruhe, Germany). According to the manufacturer, it has a molecular weight of $\sim 160 \mathrm{kDa}$. Throughout the paper, it will be abbreviated as MC.

Two material mixtures have been prepared: one soy protein isolate without MC and one with the addition of $10 \%$ MC. These were prepared to a moisture content of $51.7 \%$. For preparation of the mixtures, the necessary quantity of water was added to the solid material and vigorously mixed in a Thermomix (Vorwerk, Wuppertal, Germany). Before the rheological measurements, samples were kept in the refrigerator at $8^{\circ} \mathrm{C}$ for at least $16 \mathrm{~h}$ to guarantee equilibrium of hydration. Both mixtures were pre- 
pared in triplicate; all measurements were performed at least three times per mixture $(3 \times 3)$.

\subsection{Methods}

\subsubsection{Rheological characterization}

The rheological characterization of samples was conducted using a closed cavity rheometer (RPA Flex, TA Instruments). A cross section of the rheometer die design is shown in Figure 1.

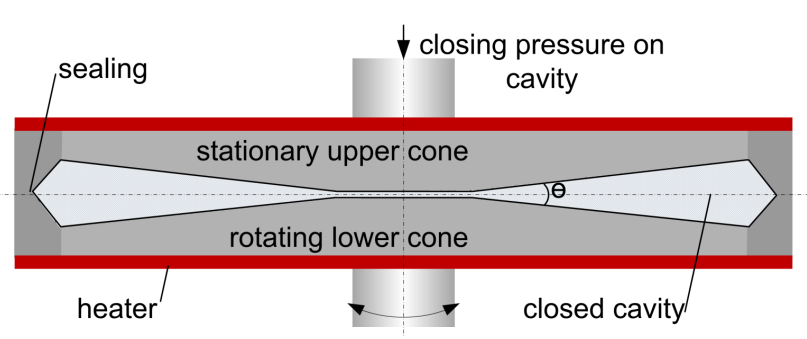

Figure 1: Schematic illustration of the closed cavity rheometer cell used for rheological characterization.

In this device, the sample is loaded between the two cones. The experiments were performed, as the lower cone was driven by a motor in an oscillatory movement, where the applied deformation was defined by setting the excitation frequency and shear strain amplitude. The torque applied from the studied material to the lower cone of the rheometer was then measured. This way, the strain was controlled and the stress response of the material under deformation was recorded and analyzed.

The cavity geometry is bi-conical with an opening half angle of $3.35^{\circ}$ to transmit the shear stress on a sample volume homogenously. Moreover, the cones have large grooves to prevent slippage. The sample mass was $5.5 \mathrm{~g}$ and constant for all measurements. A fully filled cavity is necessary for the measurements and is achieved by loading the device with a slight excess of material, which is pushed outside of the measurement cavity when the cones close.

The sample in this apparatus was kept in a sealed cavity which was pressurized up to $4500 \mathrm{kPa}$ during the experiment to prevent moisture loss and facilitate protein plasticization. The process of plasticization can be observed in Figure 2, where the soy protein matrix before and after measurement in the closed cavity rheometer is shown.

The soy protein isolate mixed with water is a brittle, powdery matrix. Through the normal forces of the cones,

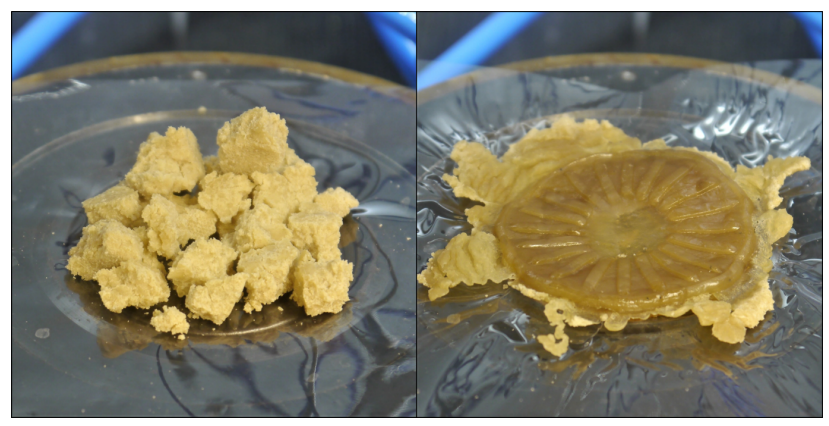

Figure 2: Soy protein matrix with a moisture content of $51.7 \%$ before (left) and after (right) measurement in the closed cavity rheometer.

homogenous plasticization of the protein takes place. Excessive material, that was pushed outside of the cavity and was therefore not pressurized, remains brittle and powdery.

In the present setting of the rheometer, the motor was configured to enable deformation of very highly viscous materials (application of high forces). Thus, the sensitivity of the torque sensor was not low enough to be able to measure materials with moderately high viscosity in a reproducible manner. Therefore, the temperature of the cavity was chosen to be $60^{\circ} \mathrm{C}$ for all measurements, as at this temperature the viscosity of the samples was high enough and the measurements were reproducible.

Thermal material stability was checked for both recipes with time sweeps at $60^{\circ} \mathrm{C}$ (results not shown) confirming that no changes in the molecular structure (i.e., molecular aggregation/degradation) occurred during the course of one measurement routine.

\subsubsection{Strain sweep}

Strain sweeps were performed at constant angular frequency of $\omega=6.28 \mathrm{rad} / \mathrm{s}$. The strain increased gradually and logarithmically from $\gamma=0.19 \%$ to $501 \% . G^{\prime}$ and $G^{\prime \prime}$ were determined as a function of $\gamma$.

\subsubsection{Frequency sweep}

Frequency sweeps were performed in the linear viscoelastic range (determined from strain sweeps) of both materials at a constant strain of $\gamma=0.98 \%$. The angular frequency increased gradually and logarithmically from 0.87 to $314.16 \mathrm{rad} / \mathrm{s}$. $\mathrm{G}^{\prime}, \mathrm{G}^{\prime \prime}$ and $\eta^{\star}$ were determined as a function of $\omega$. 


\subsubsection{LAOS measurements}

LAOS measurements were performed at a constant angular frequency of $\omega=6.28 \mathrm{rad} / \mathrm{s}$. In a first step, material was treated at $\gamma=0.98 \%$ and $\omega=6.28 \mathrm{rad} / \mathrm{s}$ for $\mathrm{t}=4 \mathrm{~min}$ to reduce inner stresses. In the second step, a strain sweep was performed. Each strain was applied for 40 cycles (240 cycles in total). The strain increased gradually: $\gamma=1,5$, $10,25,80,200 \%$. For data analysis, the MITlaos program was used, which was developed for the analysis of LAOS measurements at the Massachusetts Institute of Technology (MIT) [79]. The oscillatory data of strain $\gamma$ and shear stress $\tau$ of the strain-controlled measurements was used as input for the program. Only stationary data was used for analysis to describe the material response precisely.

Normalized shear stress as a function of normalized strain can be plotted in so-called Lissajous-Bowditch figures [78]. For this purpose, shear stress $\tau$ and deformation $\gamma$ were normalized to their maximal values. As a way to quantify the geometrical features of these figures, the zero strain modulus, $\mathrm{G}_{M}^{\prime}$, the large strain modulus, $\mathrm{G}_{L}^{\prime}$, and the stiffening ratio, $\mathrm{S}$, were calculated.

\subsubsection{Stress relaxation test}

The stress relaxation test was performed in two steps. In the first step, a "recovery" phase, the material was treated at $\gamma=0.98 \%$ and $\omega=6.28 \mathrm{rad} / \mathrm{s}$ for $\mathrm{t}=75 \mathrm{sec}$. This should level out possible effects which were already acting on the test material during sample preparation [81]. Subsequently, the material was deformed with a strain of $\gamma=$ $80 \%$ for $\mathrm{t}=4 \mathrm{~min}$. The shear stress $\tau$ was determined as a function of the time.

\section{Results and Discussion}

\subsection{Analysis of rheological properties in strain sweep}

Small amplitude oscillatory shear tests (SAOS) are performed in the linear viscoelastic (LVE) range of the material. To determine the LVE, a strain sweep is performed. At a constant frequency and temperature, strains from low to high are applied to the material and the response is recorded and evaluated. In Figure 3, a strain sweep of the model system is depicted. The storage $\left(\mathrm{G}^{\prime}\right)$ and loss $\left(\mathrm{G}^{\prime \prime}\right)$ moduli are plotted as a function of the strain $(\gamma)$.

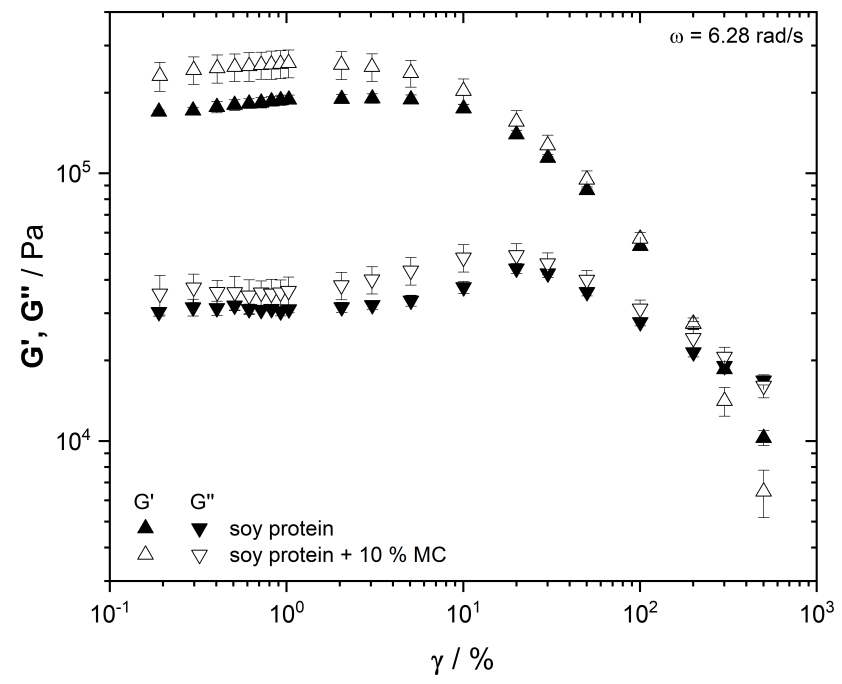

Figure 3: Strain sweep of the model system $(\boldsymbol{\Lambda} / \mathbf{\nabla}=$ soy protein, $\Delta / \nabla$ $=$ soy protein $+10 \% \mathrm{MC})$ at $\omega=6.28 \mathrm{rad} / \mathrm{s}$.

The LVE range can be defined up to a maximum strain $\gamma_{L}$, where $\mathrm{G}^{\prime}$ remains at a constant value [81]. $\gamma_{L}$ was visually determined to be $10 \%$ for both model systems. In the LVE, the elastic behavior dominates over the viscous behavior; $G^{\prime}$ is around 10 times higher than $G^{\prime \prime}$, which is an indicator of gel character [81].

This elastic behavior of plasticized soy proteins reflects in the often chewy, rubber-like texture of soy-based meat analogues, but is also obvious in the plasticized matrix in Figure 4.

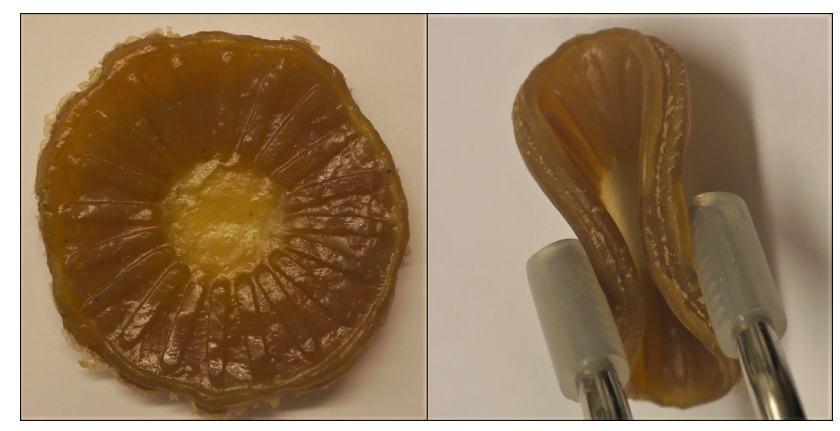

Figure 4: Elasticity of the plasticized soy protein after measurement, visualized by manual deformation. The deformation is completely reversible.

The flow point $\left(\mathrm{G}^{\prime}=\mathrm{G}^{\prime \prime}\right)$ is reached at $\gamma_{F}=300 \%$. At higher strain, the viscous behavior dominates and the sample behaves as a liquid.

A strain of $300 \%$ and frequency of $6.28 \mathrm{rad} / \mathrm{s}$ equal a maximum shear rate of $18.85 \mathrm{~s}^{-1}$, which is easily reached in the screw section of an extruder [4], whereas the lower shear rates can be found in the die section, demonstrating 

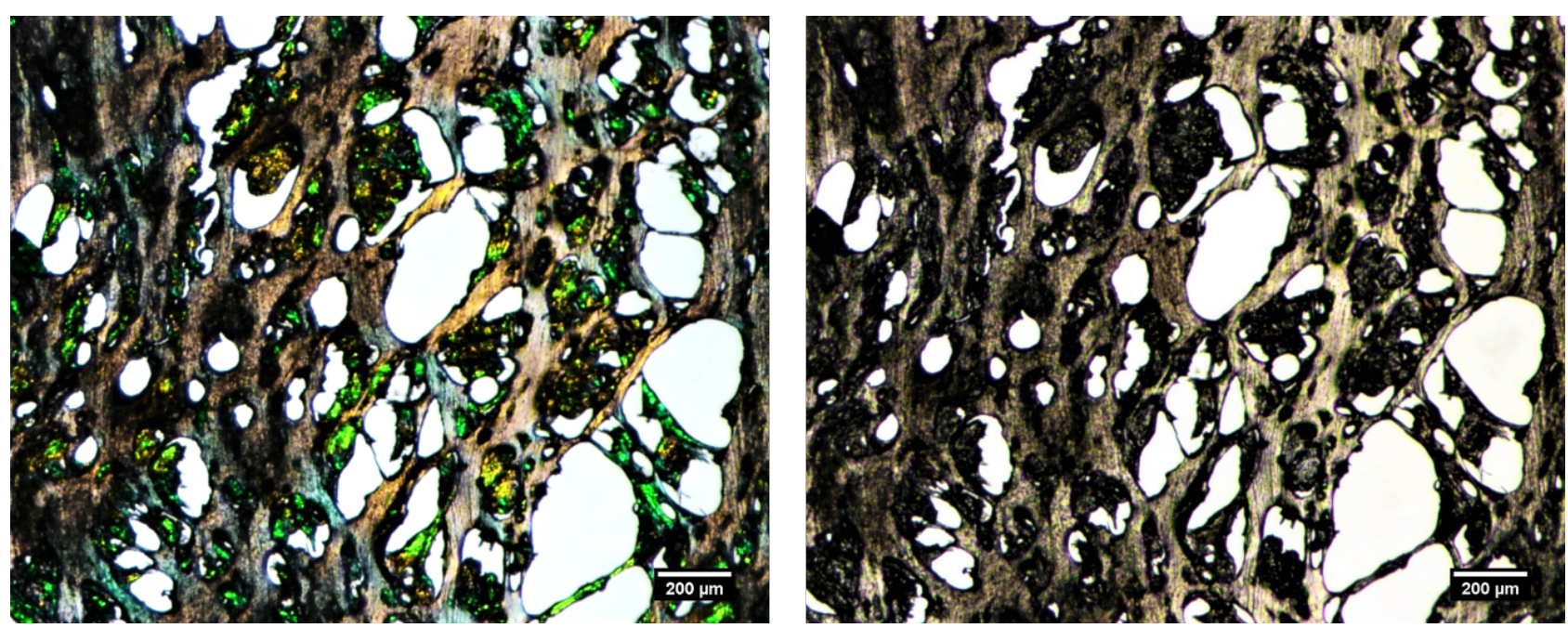

Figure 5: Microscopic images of a $40 \mu \mathrm{m}$ - slice from an extruded soy protein $-\mathrm{MC}$ matrix $\left(\mathrm{T}_{\text {Material }}=125^{\circ} \mathrm{C}, \mathrm{n}=250 \mathrm{rpm}\right)$. Images taken with (left) and without (right) polarization filter in a conventional light microscope.

the necessity of the measurements in both linear and nonlinear region.

The loss modulus $\mathrm{G}^{\prime \prime}$ first increases, then decreases with increasing strain, showing a peak at $\gamma=20 \%$. This behavior has been described as "weak strain overshoot" [82] and can be an indicator for the occurrence of micro cracks in the matrix with increasing strain, leading to an increase of internal friction and therefore of $G^{\prime \prime}$, while the overall structure remains unchanged (constant $\mathrm{G}^{\prime}$ ). Then, reaching the critical strain, a macro crack appears leading to the overall structure loss and decrease in both $\mathrm{G}^{\prime}$ and $\mathrm{G}^{\prime \prime}$. Nevertheless, thorough interpretation of this behavior by physical or chemical mechanisms remains challenging and, depending on the material, different authors have suggested different causes of the overshoot behavior.

The addition of MC to the soy protein leads to an increase in $\mathrm{G}^{\prime}$ of around $30-40 \%$ in the LVE. This effect is expected to be due to the ability of MC to form elastic gels at temperatures above $52^{\circ} \mathrm{C}$ [76].

The formation of a dispersed phase could be a possible explanation for the decrease of $\mathrm{G}^{\prime}$ by $40 \%$ at the highest strain of 500\%; an influence of the dispersed phase morphology on the rheological properties in the non-linear range has been reported already [83]. If the investigated material (soy protein $+10 \% \mathrm{MC})$ is extruded $\left(\mathrm{T}_{\text {Material }}=\right.$ $125^{\circ} \mathrm{C}, n=250 \mathrm{rpm}$ ), a dispersed phase is formed. This is depicted in Figure 5.

$\mathrm{MC}$ is known to form (partially) crystalline structures, and ordered structures appear green if polarization filters are used. The green dispersed phase is therefore expected to consist of MC; also, extrudates without MC do not show this green phase. Although these structures were obtained from a material after extrusion at high temperatures, it is assumed that a dispersed phase is formed at the temperature of rheological analysis as well. However, for this material system, the interpretation of precise correlations is speculative and should be further investigated.

\subsection{Analysis of rheological properties in the linear range}

To investigate the time-dependent behavior of the material, frequency sweeps are performed. These tests were carried out in the LVE range, with an amplitude of $\gamma=0.98 \%$. The frequency sweep of the model system is depicted in Figure 6.

Similar trends as in the strain sweeps are visible in the viscoelastic moduli. $\mathrm{G}^{\prime}$ is always higher than $\mathrm{G}^{\prime \prime}$ by an order of magnitude, indicating a gel-like behavior for both material systems. The almost frequency-independent, parallel lines of $\mathrm{G}^{\prime}$ and $\mathrm{G}^{\prime \prime}$ also indicate gel-like interactions between the proteins [84]. Time sweeps have shown no reactivity in the system, therefore crosslinking through covalent interactions such as disulphide bonds cannot be the explanation. Non-covalent interactions and polymer entanglements (due to the high concentration) are expected to cause the interactions between proteins.

The addition of MC leads to an increase of $\mathrm{G}^{\prime}$, while $G^{\prime \prime}$ remains unchanged, showing the same trend as in the strain sweep: elastic behavior increases.

Complex viscosity $\eta^{\star}$ decreases with increasing frequency. Analogue correlations between the viscosity $\eta$ and the shear rate $\dot{\gamma}$ have been reported for concentrated soy 


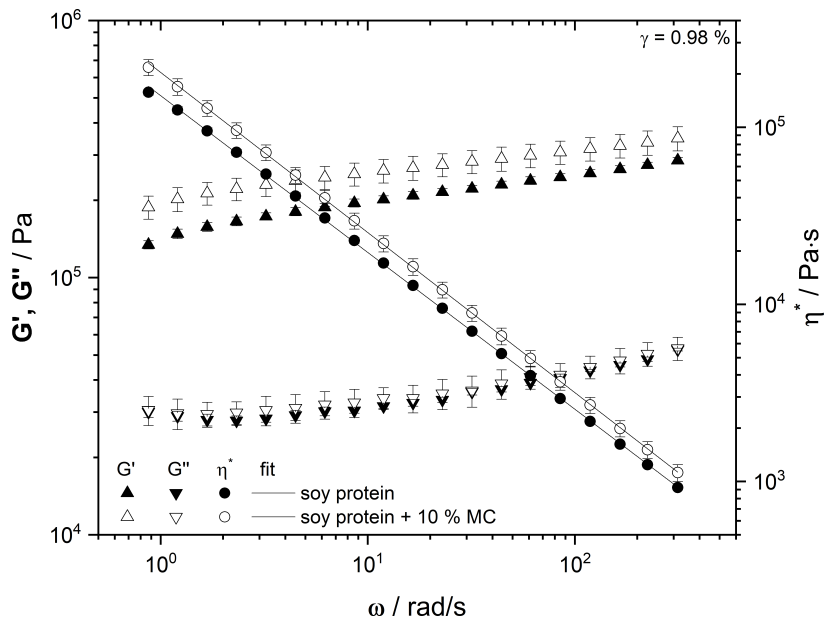

Figure 6: Frequency sweep of the model system $(\Lambda / \mathbf{v} / \bullet=$ soy protein, $\Delta / \nabla / 0=$ soy protein $+10 \% M C$ ) at $\gamma=0.98 \%$. The solid lines represent power-law fits of the complex viscosity.

protein isolate in earlier work $[31,37,38,85]$ with conventional rotatory and capillary rheometers.

The viscosity data can be fitted with the Power-Law model [86]:

$$
\eta^{\star}(\omega)=K \cdot \omega^{n},
$$

where $K$ is the consistency coefficient with the unit $\mathrm{Pa} \cdot \mathrm{s}^{n}$ and $n$ the flow behavior index (dimensionless). This gives the values shown in Table 1.

Table 1: Values of the power-law fit for complex viscosity of soy protein and soy protein with $10 \%$ methylcellulose. $R^{2}>0.999$ for both fits.

\begin{tabular}{rcc}
\hline & Soy Protein & Soy Protein with $10 \% \mathrm{MC}$ \\
\hline $\mathrm{K}\left[\mathrm{Pa} \cdot \mathrm{s}^{n}\right]$ & 150621 & 203748 \\
$\mathrm{n}[-]$ & -0.885 & -0.904 \\
\hline
\end{tabular}

The values of the flow behavior index $\mathrm{n}$ are comparable to those of Chen et al. [45], who reported a value of -0.873 for an extruded soy dough. The values close to -1 imply a relatively high dependence between deformation and viscosity.

\subsection{Analysis of rheological properties in the non-linear range (LAOS)}

The frequency sweep in Figure 6 was performed in the LVE range of the material (SAOS), where stress response to the strain is always linear. In the strain sweep Figure 3, LVE was determined to end at $\gamma_{L}=10 \%$ for both model systems. To investigate the rheological behavior outside the LVE range (nLVE), strain sweeps at $\omega=6.28 \mathrm{rad} / \mathrm{s}$ for deformations $\gamma=1,5,10,25,80,200 \%$ were performed. For better visibility, only the corresponding elastic LissajousBowditch plots [78] of the material responses for $\gamma=5,25$, $80,200 \%$ are depicted in Figure 7.

At the lowest deformation of $5 \%$, which is, according to the strain sweep, still in the linear range for both material systems, the plots are elliptical and smooth, indicating linear material response. The elliptical, smooth shape indicates that the material is viscoelastic, and elastic behavior dominates in the linear range.

At higher deformations of $\gamma>25 \%$, the plot shape changes; it becomes less elliptical and the surface area increases, indicating an increase in viscous behavior. The rate of dissipated energy increases [78]. With further increasing deformation $(\gamma=80,200 \%)$, the shape becomes more distorted. This distortion is an indicator for the occurrence of higher harmonics in the material response [87].

Comparing the plots of both model systems at $\gamma=$ $200 \%$, it can be seen that both surface area and distortion increase with the addition of MC. The surface area can be related with an increase in viscous behavior, while the increase of distortion indicates that MC addition leads to an increase in non-linearities in the material response.

To further characterize the rheological properties in the non-linear regime, new measures have been introduced [79]. The linear elastic modulus $\mathrm{G}^{\prime}(\omega)$ is not sufficient to describe elastic behavior for a non-linear material response. Therefore, the zero strain modulus $\mathrm{G}_{M}^{\prime}$ and the large strain modulus $\mathrm{G}_{L}^{\prime}$ are introduced. These parameters can give additional physical insights when analyzing a non-linear signal and also have a geometrical representation in the Lissajous-Bowditch figures. In the linear range, it is $\mathrm{G}_{L}^{\prime}=\mathrm{G}_{M}^{\prime}=\mathrm{G}^{\prime}$, whereas in the non-linear range, higher harmonics appear and therefore the moduli are not equal: $\mathrm{G}_{L}^{\prime} \neq \mathrm{G}_{M}^{\prime} \neq \mathrm{G}^{\prime}$.

The zero strain modulus $\mathrm{G}_{M}^{\prime}$ describes the behavior inside one strain cycle at the deformation of $\gamma=0 \%$, using the slope of the Lissajous-Bowditch Plot at zero-crossing as the describing value. $\mathrm{G}_{M}^{\prime}$ is plotted as a function of strain in Figure 8.

For small strains up to $5-10 \%, \mathrm{G}_{M}^{\prime}$ remains almost constant. Same behavior can be seen in the strain sweep (Figure 3), where $G^{\prime}$ and $G^{\prime \prime}$ also remain constant at small strains. With further increasing strain, the modulus decreases. This is an indicator for the so-called "overall strain softening", which is typical for biopolymers. With increasing deformation, the polymer chains of the soy 
a

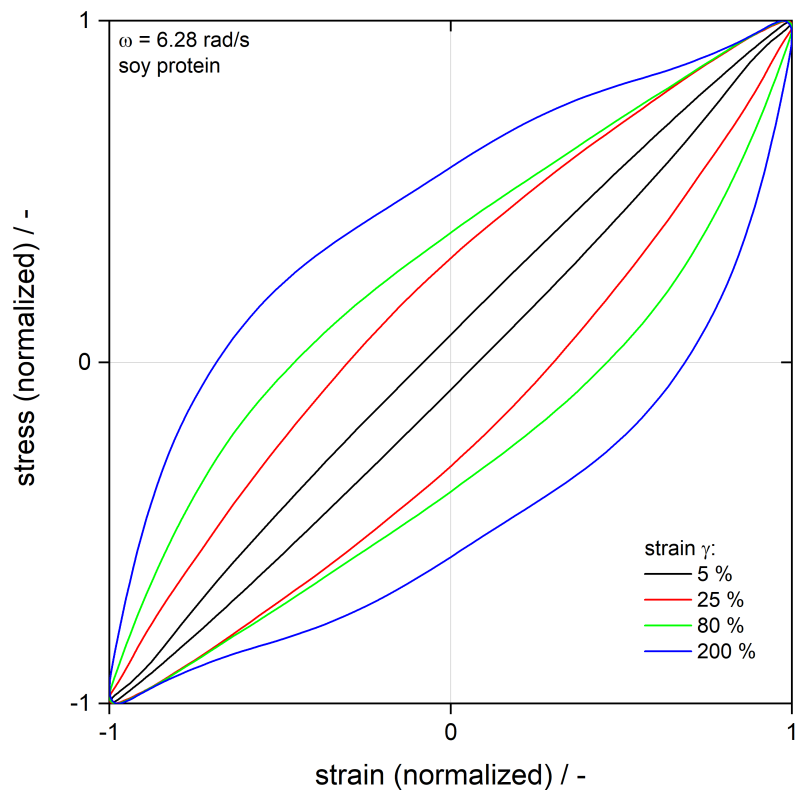

b

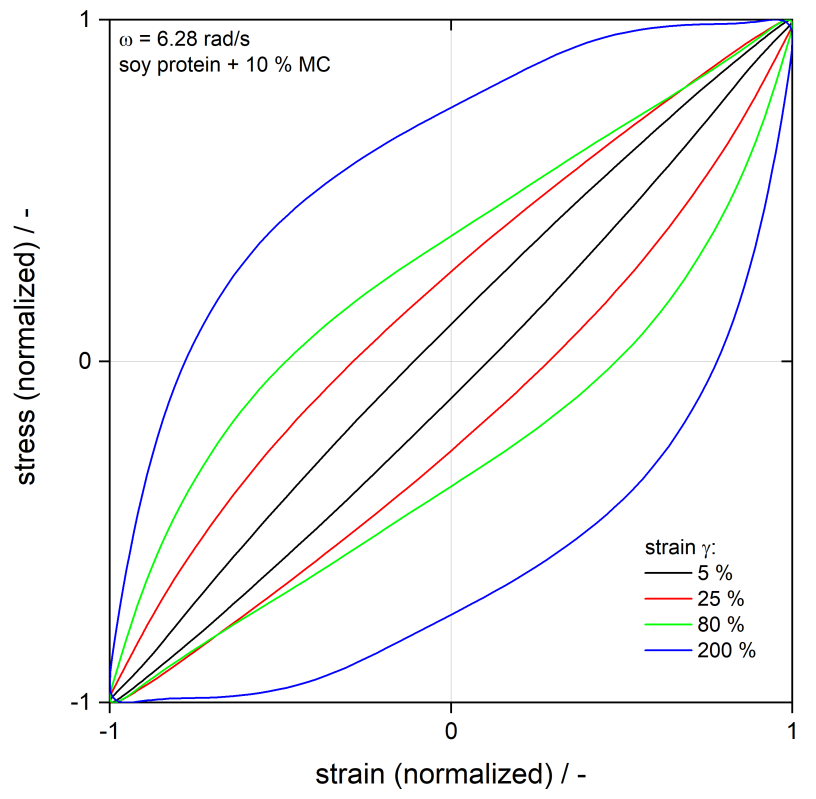

Figure 7: Lissajous-Bowditch Plots of the elastic part of material response from soy protein (a) and soy protein with $10 \%$ MC (b) at deformations of $\gamma=5,25,80$ and $200 \%$. Exemplary raw data is given in the appendix.

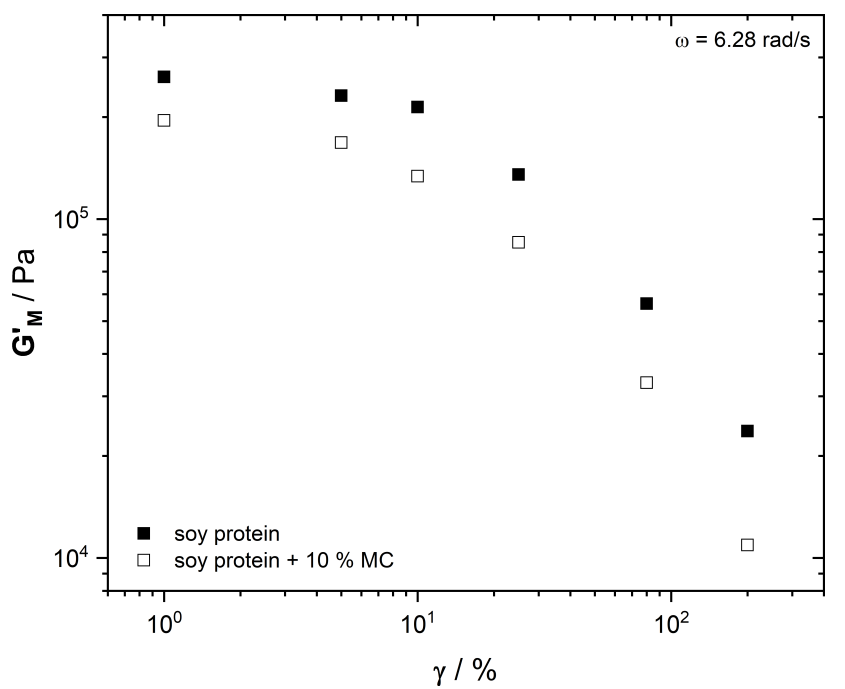

Figure 8: Zero Strain Modulus $\mathrm{G}_{M}^{\prime}$ as a function of strain $\gamma$ for soy protein (filled squares) and soy protein $+10 \%$ MC (empty squares).

protein experience reorientation/arrangement, while no break-up of intramolecular bonds takes place [88].

To describe local (inside one strain cycle) changes of the material, the stiffening ratio, $S$, is introduced:

$$
S=\frac{G_{L}^{\prime}-G_{M}^{\prime}}{G_{L}^{\prime}}
$$

where $\mathrm{G}_{L}^{\prime}$ is the large strain modulus, that describes the slope of a line between the zero point and the point of maximum strain $\gamma_{\max }$ in a Lissajous-Bowditch plot. In the lin-

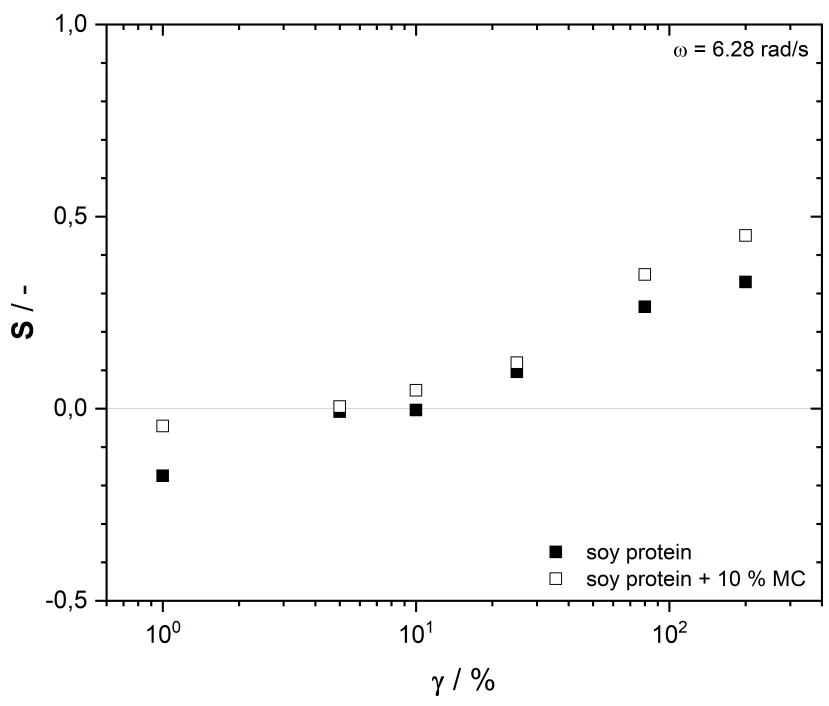

Figure 9: Stiffening ratio $S$ as a function of strain $\gamma$ for soy protein (filled squares) and soy protein $+10 \%$ MC (empty squares).

ear range, it is $\mathrm{G}_{L}^{\prime}=\mathrm{G}_{M}^{\prime}=\mathrm{G}^{\prime}$, and therefore $S=0$. In Figure 9, the stiffening ratio $S$ is plotted as a function of strain.

For small strains, the value of the stiffening ratio is close to zero. With increasing strain, the stiffening ratio increases. This behavior is described as intracycle stiffening [89]. Through the deformation during one strain cycle, entanglement of the polymer chains can occur, which leads to a short-term stiffening of the material's structure and the increase of the stiffening ratio $S$. This behavior is 
shown in Figure 9. With a further increase of deformation (higher than $\gamma=200 \%$ ) it can be expected that the stiffening ratio would decrease again, as the material structure is only capable of resisting certain forces [88]. The addition of MC leads to an increase of $S$ for all strains.

\subsection{Stress relaxation test}

Stress relaxation tests were also performed on the material. In a stress relaxation test, a fixed deformation/strain is applied to the material very quickly and the stress needed to hold the deformation is recorded. An ideal viscous material relaxes instantly, while an ideal elastic material does not relax at all. A viscoelastic material shows a gradual decrease in stress, while the end point depends on the molecular structure of the material.

The results of the relaxation test for a strain of $80 \%$ are depicted in Figure 10. The stress $\tau$ is plotted over time.

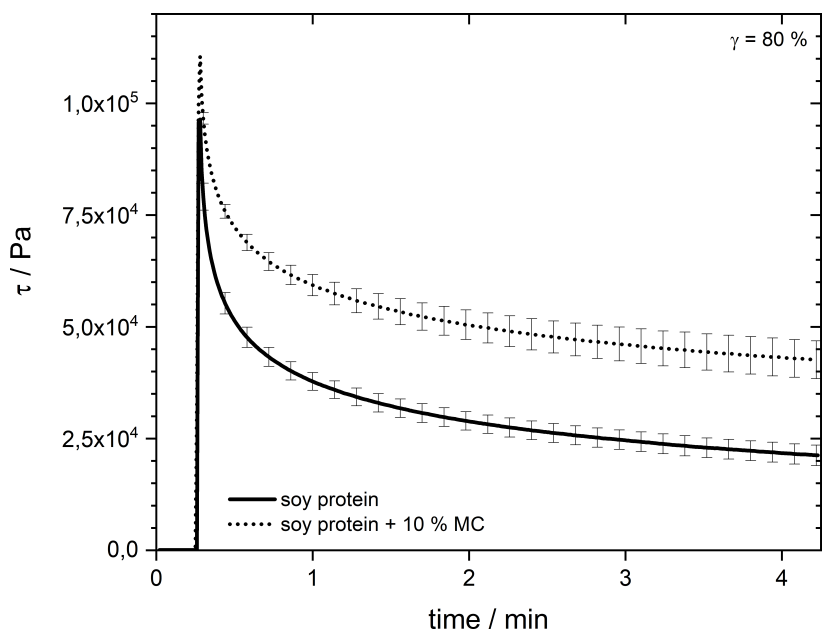

Figure 10: Stress relaxation test of the model system at $\gamma=80 \%$. Solid line is soy protein, dotted line is soy protein with $10 \%$ MC.

After a preparation phase, a sudden, rapid strain of $80 \%$ is applied to the material. The gradual decrease of stress indicates a viscoelastic material response. The maximum shear stress $\tau$ achieved for SPI is approximately $96 \mathrm{kPa}$, while with the addition of $10 \% \mathrm{MC}$, the stress increases to approximately $110 \mathrm{kPa}$. The maximum shear stress can be interpreted as a measure for elasticity, leading to the conclusion that the addition of MC leads to the expected increase in elasticity of the system.

\section{Conclusion}

Rheological properties play a crucial role in extrusion processing of highly concentrated biopolymers. Both viscous and elastic properties have an influence on the process conditions and product properties. As deformations range from low to very high in the process, rheological analysis must be carried out in both linear and non-linear viscoelastic range. Measurements with a closed cavity rheometer allowed us to gain extensive information on the processrelevant rheological properties of a model biopolymer, i.e., soy protein. The normal forces acting on the protein in the cavity facilitated protein plasticization, an indispensable requirement for physically meaningful measurements and not achievable with alternative, conventional rheometers. In the linear range, $G^{\prime}$ showed higher values than $G^{\prime \prime}$ by an order of a magnitude, indicating gel-like behavior. Liquidlike behavior $\left(\mathrm{G}^{\prime \prime}>\mathrm{G}^{\prime}\right)$ was achieved at $\gamma=300 \%$ (which corresponds to a shear rate of $18.85 \mathrm{~s}^{-1}$ ), indicating the importance of analyzing the process-relevant rheological properties in the non-linear viscoelastic range. The curvatures of $G^{\prime}$ and $G^{\prime \prime}$ can be classified as "weak strain overshoot", showing resistance of polymer chains against small deformations. The frequency sweep revealed a high dependence of the complex viscosity from the frequency. In the non-linear range, LAOS measurements were conducted and analyzed. Increasing strain led to an increase in elliptical distortion and viscous dissipation. The stiffening ratio increased with increasing strain, indicating intracycle stiffening. The stress relaxation tests showed the viscoelastic behavior of the material. In all measurements, addition of MC led to the expected increase of elastic properties of the material. Furthermore, the addition of MC resulted in changes of the rheological behavior in the nonlinear range, i.e., higher distortion and viscous dissipation.

The measurement procedure provided an extensive insight into the rheological properties of a model biopolymer at an extrusion-relevant water content and a temperature of $60^{\circ} \mathrm{C}$. This specific rheometer setup could also enable future studies on rheological characterization at even higher measurement temperatures, which are common in many extrusion processes, and of various other biopolymers.

Acknowledgement: This research project was supported by the German Ministry of Economics and Energy (via AiF) and FEI (Forschungskreis der Ernährungsindustrie e.V., Bonn) in the scope of project AiF 20249 N. We also acknowledge support by the KIT-Publication Fund of the Karlsruhe Institute of Technology. 


\section{References}

[1] Emin M.A., Schuchmann H.P., A mechanistic approach to analyze extrusion processing of biopolymers by numerical, rheological, and optical methods, Trends Food Sci. Tech., 2017, 60, 88-95.

[2] Bouvier J.-M., Campanella O., Extrusion processing technology: Food and non-food biomaterials, Chichester, West Sussex, UK: John Wiley \& Sons Inc, 2014.

[3] Guy R.C.E., Extrusion cooking: Technologies and applications, Woodhead Publishing in food science and technology, Boca Raton, Fla, Cambridge, England: CRC Press, 2001.

[4] Emin M.A., Schuchmann H.P., Analysis of the dispersive mixing efficiency in a twin-screw extrusion processing of starch based matrix, J. Food Eng., 2013, 115(1), 132-143.

[5] van den Einde R.M., Akkermans C., van der Goot A.J., Boom R.M., Molecular breakdown of corn starch by thermal and mechanical effects, Carbohydr. Polym., 2004, 56(4), 415-422.

[6] Emin M.A., Schuchmann H.P., Droplet breakup and coalescence in a twin-screw extrusion processing of starch based matrix, J. Food Eng., 2013, 116(1), 118-129.

[7] Lai L.S., Kokini J.L., Physicochemical changes and rheological properties of starch during extrusion. (A review), Biotechnol. Prog., 1991, 7(3), 251-266.

[8] Valle G.D., Vergnes B., Colonna P., Patria A., Relations between rheological properties of molten starches and their expansion behaviour in extrusion, J. Food Eng., 1997, 31(3), 277-295.

[9] Robin F., Dattinger S., Boire A., Forny L., Horvat M., Schuchmann H.P., et al., Elastic properties of extruded starchy melts containing wheat bran using on-line rheology and dynamic mechanical thermal analysis, J. Food Eng., 2012, 109(3), 414-423.

[10] Horvat M., Emin M.A., Hochstein B., Willenbacher N., Schuchmann H.P., Influence of medium-chain triglycerides on expansion and rheological properties of extruded corn starch, Carbohydr. Polym., 2013, 93(2), 492-498.

[11] Cheftel J.C., Kitagawa M., Quéguiner C., New protein texturization processes by extrusion cooking at high moisture levels, Food Rev. Int., 1992, 8(2), 235-275.

[12] Tolstoguzov V.B., Thermoplastic extrusion-the mechanism of the formation of extrudate structure and properties, J. Am. Oil Chem. Soc., 1993, 70(4), 417-424.

[13] Akdogan H., High moisture food extrusion, Int. J. Food Sci. Nutr., 1999, 34(3), 195-207.

[14] Pietsch V.L., Werner R., Karbstein H.P., Emin M.A., High moisture extrusion of wheat gluten: Relationship between process parameters, protein polymerization, and final product characteristics, J. Food Eng., 2019, 259, 3-11.

[15] Xie F., Halley P.J., Avérous L., Rheology to understand and optimize processibility, structures and properties of starch polymeric materials, Prog. Polym. Sci., 2012, 37(4), 595-623.

[16] Wittek P., Emin M.A., Three-Dimensional modeling of food extrusion processes, Reference Module in Food Sciences, 2017.

[17] Wittek P., Pereira G.G., Emin M.A., Lemiale V., Cleary P.W., Accuracy analysis of SPH for flow in a model extruder with a kneading element, Chem. Eng. Sci., 2018, 187, 256-268.

[18] Ishikawa T., Kihara S.-i., Funatsu K., 3-D non-isothermal flow field analysis and mixing performance evaluation of kneading blocks in a co-rotating twin srew extruder, Polym. Eng. Sci., 2001, 41(5), 840-849.
[19] Cheng H., Manas-Zloczower I., Distributive mixing in conveying elements of a ZSK-53 co-rotating twin screw extruder, Polym. Eng. Sci., 1998, 38(6), 926-935.

[20] Cornec M., Popineau Y., Lefebvre J., Characterisation of Gluten Subfractions by SE-HPLC and Dynamic Rheological Analysis in Shear, J. Cereal Sci., 1994, 19(2), 131-139.

[21] Madeka H., Kokini J.L., Changes in rheological properties of gliadin as a function of temperature and moisture: Development of a state diagram, J. Food Eng., 1994, 22(1-4), 241-252.

[22] Khatkar B.S., Bell A.E., Schofield J.D., The dynamic rheological properties of glutens and gluten sub-fractions from wheats of good and poor bread making quality, J. Cereal Sci., 1995, 22(1), 29-44.

[23] Hargreaves J., Popineau Y., Cornec M., Lefebvre J., Relations between aggregative, viscoelastic and molecular properties in gluten from genetic variants of bread wheat, Int. J. Biol. Macromol., 1996, 18(1-2), 69-75.

[24] Janssen A.M., van Vliet T., Vereijken J.M., Rheological behaviour of wheat glutens at small and large deformations: comparison of two glutens differing in bread making potential, J. Cereal Sci., 1996, 23(1), 19-31.

[25] Redl A., Morel M.H., Bonicel J., Guilbert S., Vergnes B., Rheological properties of gluten plasticized with glycerol: dependence on temperature, glycerol content and mixing conditions, Rheol. Acta, 1999, 38(4), 311-320.

[26] Rao V.K., Mulvaney S.J., Dexter J.E., Rheological characterisation of long- and short- mixing flours based on stress-relaxation, J. Cereal Sci., 2000, 31(2), 159-171.

[27] Uthayakumaran S., Small and large strain rheology of wheat gluten, Rheol. Acta, 2002, 41(1-2), 162-172.

[28] Tronsmo K.M., Magnus E.M., Baardseth P., Schofield J.D., Aamodt A., Færgestad E.M., Comparison of small and large deformation rheological properties of wheat dough and gluten, Cereal Chem., 2003, 80(5), 587-595.

[29] Lefebvre J., An outline of the non-linear viscoelastic behaviour of wheat flour dough in shear, Rheol. Acta, 2006, 45(4), 525-538.

[30] Ng T.S.K., McKinley G.H., Ewoldt R.H., Large amplitude oscillatory shear flow of gluten dough: A model power-law gel, J. Rheol., 2011, 55(3), 627-654.

[31] Baird D.G., Dynamic viscoelastic properties of soy isolate doughs, J. Texture Stud., 1981, 12(1), 1-16.

[32] Jasberg B.K., Taylor N.W., Mustakas G.C., Bagley E.B., Determination of dynamic moduli of soy doughs using an orthogonal rheometer, J. Texture Stud., 1981, 12(3), 307-319.

[33] Baird D.G., The effect of heat and shear on the viscoelastic properties of soy flour dough, J. Food Process Eng., 1982, 5(4), 231-245.

[34] Rao M.A., Measurement of flow properties of fluid foods - developments, limitations, and interpretation of phenomena, J. Texture Stud., 1977, 8(3), 257-282.

[35] Steffe J.F., Rheological methods in food process engineering, 2nd ed., East Lansing, MI: Freeman Press, 1996.

[36] Bresnahan D.P., Wolf J.C., Thompson D.R., Potential for utilizing $11 \mathrm{~S}$ soy globular protein to study texture formation, J. Food Process Eng., 1981, 5(2), 113-123.

[37] Fujio Y., Hayashi N., Hayakawa I., Effect of moisture content on flow behaviour of molten soy-protein isolate under an elevated temperature, Int. J. Food Sci. Nutr., 1991, 26(1), 45-51.

[38] Hayashi N., Hayakawa I., Fujio Y., Entrance effect correction on the flow of moisturized soy protein isolate melt in an extrusion viscometer, Int. J. Food Sci. Nutr., 1991, 26(6), 567-574. 
[39] Hayashi N., Hayakawa I., Fujio Y., Hydration of heat-treated soy protein isolate and its effect on the molten flow properties at an elevated temperature, Int. J. Food Sci. Nutr., 1992, 27(5), 565-571.

[40] Hayashi N., Noma K., Hayakawa I., Fujio Y., Influence of timetemperature history and strain history on the melt rheology of soy protein isolate at an elevated temperature, Int. J. Food Sci. Nutr., 1992, 27(3), 297-304.

[41] Hayashi N., Hayakawa I., Fujio Y., Flow behaviour of soy protein isolate melt with low and intermediate moisture levels at an elevated temperature, J. Food Eng., 1993, 18(1), 1-11.

[42] Vergnes B., Villemaire J.P., Rheological behaviour of low moisture molten maize starch, Rheol. Acta, 1987, 26(6), 570-576.

[43] Emin M.A., Quevedo M., Wilhelm M., Karbstein H.P., Analysis of the reaction behavior of highly concentrated plant proteins in extrusion-like conditions, Innovative Food Science \& Emerging Technologies, 2017, 44, 15-20.

[44] McMaster T.J., Senouci A., Smith A.C., Measurement of rheological and ultrasonic properties of food and synthetic polymer melts, Rheol. Acta, 1987, 26(3), 308-315.

[45] Chen A.H., Jao Y.C., Larkin J.W., Goldstein W.E., Rheological model of soy dough in extrusion, J. Food Process Eng., 1978, 2(4), 337342.

[46] Jasberg B.K., Mustakas G.C., Bagley E.B., Effect of extruder retention time on capillary flow of soy dough, J. Food Process Eng., 1982, 5(1), 43-56.

[47] Bhattacharya M., Hanna M.A., Viscosity modelling of dough in extrusion, Int. J. Food Sci. Nutr., 1986, 21(2), 167-174.

[48] Senouci A., Smith A.C., An experimental study of food melt rheology, Rheol. Acta, 1988, 27(5), 546-554.

[49] Bengoechea C., Arrachid A., Guerrero A., Hill S.E., Mitchell J.R., Relationship between the glass transition temperature and the melt flow behavior for gluten, casein and soya, J. Cereal Sci., 2007, 45(3), 275-284.

[50] Ralston B.E., Osswald T.A., Viscosity of soy protein plastics determined by screw-driven capillary rheometry, J. Polym. Environ., 2008, 16(3), 169-176.

[51] Beck S.M., Knoerzer K., Sellahewa J., Emin M.A., Arcot J., Effect of different heat-treatment times and applied shear on secondary structure, molecular weight distribution, solubility and rheological properties of pea protein isolate as investigated by capillary rheometry, J. Food Eng., 2017, 208, 66-76.

[52] Dail R. v., Steffe J.F., Rheological characterization of crosslinked waxy maize starch solutions under low acid aseptic processing conditions using tube viscometry techniques, J. Food Sci., 1990, 55(6), 1660-1665.

[53] Padmanabhan M., Bhattacharya M., Flow behavior and exit pressures of corn meal under high-shear-high-temperature extrusion conditions using a slit die a), J. Rheol., 1991, 35(3), 315-343.

[54] Vergnes B., Della Valle G., Tayeb J., A specific slit die rheometer for extruded starchy products. Design, validation and application to maize starch, Rheol. Acta, 1993, 32(5), 465-476.

[55] Bindzus W., Fayard G., van Lengerich B., Meuser F., Application of an in-line viscometer to determine the shear stress of plasticised wheat starch, Starch-Starke, 2002, 54(6), 243-251.

[56] Martin O., Averous L., Della Valle G., In-line determination of plasticized wheat starch viscoelastic behavior: impact of processing, Carbohydr. Polym., 2003, 53(2), 169-182.

[57] Xie F., Yu L., Su B., Liu P., Wang J., Liu H., et al., Rheological properties of starches with different amylose/amylopectin ratios, J. Cereal Sci., 2009, 49(3), 371-377.
[58] Horvat M., Azad Emin M., Hochstein B., Willenbacher N., Schuchmann H.P., A multiple-step slit die rheometer for rheological characterization of extruded starch melts, J. Food Eng., 2013, 116(2), 398-403.

[59] Bagley E.B., End corrections in the capillary flow of polyethylene, J. Appl. Phys., 1957, 28(5), 624-627.

[60] Mooney M., Explicit formulas for slip and fluidity, J. Rheol., 1931, 2(2), 210-222.

[61] Leblanc J.L., Cartault M., Advanced torsional dynamic methods to study the morphology of uncured filled rubber compounds, J. Appl. Polym. Sci., 2001, 80(11), 2093-2104.

[62] Leblanc J.L., Mongruel A., A thorough examination of a torsional dynamic rheometer with a closed oscillating cavity, Prog. Rubber Plast. Re., 2001, 17(3), 162-185.

[63] Dötsch T., Pollard M., Wilhelm M., Kinetics of isothermal crystallization in isotactic polypropylene monitored with rheology and Fourier-transform rheology, J. Phys.: Condens. Matter, 2003, 15(11), S923-S931.

[64] Pommet M., Morel M.-H., Redl A., Guilbert S., Aggregation and degradation of plasticized wheat gluten during thermomechanical treatments, as monitored by rheological and biochemical changes, Polymer, 2004, 45(20), 6853-6860.

[65] Quevedo M., Kulozik U., Karbstein H.P., Emin M.A., Kinetics of denaturation and aggregation of highly concentrated $\beta$ Lactoglobulin under defined thermomechanical treatment, J. Food Eng., 2020, 274, 109825.

[66] Quevedo M., Kulozik U., Karbstein H.P., Emin M.A., Effect of thermomechanical treatment on the aggregation behaviour and colloidal functionality of $\beta$-Lactoglobulin at high concentrations, Int. Dairy J., 2020, 104, 104654.

[67] Quevedo M., Jandt U., Kulozik U., Karbstein H.P., Emin M.A., Investigation on the influence of high protein concentrations on the thermal reaction behaviour of $\beta$-lactoglobulin by experimental and numerical analyses, Int. Dairy J., 2019, 97, 99-110.

[68] Pietsch V.L., Schöffel F., Rädle M., Karbstein H.P., Emin M.A., High moisture extrusion of wheat gluten: Modeling of the polymerization behavior in the screw section of the extrusion process, J. Food Eng., 2019, 246, 67-74.

[69] Pietsch V.L., Bühler J.M., Karbstein H.P., Emin M.A., High moisture extrusion of soy protein concentrate: Influence of thermomechanical treatment on protein-protein interactions and rheological properties, J. Food Eng., 2019, 251, 11-18.

[70] Koch L., Emin M.A., Schuchmann H.P., Reaction behaviour of highly concentrated whey protein isolate under defined heat treatments, Int. Dairy J., 2017, 71, 114-121.

[71] Koch L., Hummel L., Schuchmann H.P., Emin M.A., Influence of defined shear rates on structural changes and functional properties of highly concentrated whey protein isolate-citrus pectin blends at elevated temperatures, Food Biophys., 2017, 12(3), 309-322.

[72] Campbell M.F., Processing and product characteristics for textured soy flours, concentrates and isolates, J. Am. Oil Chem. Soc., 1981, 58(3Part2), 336-338.

[73] Wolf W.J., Soybean proteins. Their functional, chemical, and physical properties, J. Agric. Food Chem., 1970, 18(6), 969-976.

[74] Preece K.E., Hooshyar N., Zuidam N.J., Whole soybean protein extraction processes: A review, Innovative Food Science \& Emerging Technologies, 2017, 43, 163-172.

[75] Murray J.C.F., Cellulosics. In:, Handbook of Hydrocolloids, Elsevier, 2009, 710-723. 
[76] Sarkar N., Thermal gelation properties of methyl and hydroxypropyl methylcellulose, J. Appl. Polym. Sci., 1979, 24(4), 10731087.

[77] Phan-Thien N., Newberry M., Tanner R.I., Non-linear oscillatory flow of a soft solid-like viscoelastic material, J. Non-Newtonian Fluid Mech., 2000, 92(1), 67-80.

[78] Cho K.S., Hyun K., Ahn K.H., Lee S.J., A geometrical interpretation of large amplitude oscillatory shear response, J. Rheol., 2005, 49(3), 747-758.

[79] Ewoldt R.H., Hosoi A.E., McKinley G.H., New measures for characterizing nonlinear viscoelasticity in large amplitude oscillatory shear, J. Rheol., 2008, 52(6), 1427-1458.

[80] Hyun K., Wilhelm M., Klein C.O., Cho K.S., Nam J.G., Ahn K.H., et al., A review of nonlinear oscillatory shear tests: Analysis and application of large amplitude oscillatory shear (LAOS), Prog. Polym. Sci., 2011, 36(12), 1697-1753.

[81] Mezger T.G., The rheology handbook: For users of rotational and oscillation rheometers, 2nd ed., Coatings compendia, Hannover: Vincentz Network, 2006.

[82] Hyun K., Kim S.H., Ahn K.H., Lee S.J., Large amplitude oscillatory shear as a way to classify the complex fluids, J. Non-Newtonian Fluid Mech., 2002, 107(1-3), 51-65.
[83] Filipe S., Cidade M.T., Wilhelm M., Maia J.M., Evolution of morphological and rheological properties along the extruder length for blends of a commercial liquid crystalline polymer and polypropylene, Polymer, 2004, 45(7), 2367-2380.

[84] ROSS-MURPHY S.B., RHEOLOGICAL CHARACTERISATION OF GELS, J. Texture Stud., 1995, 26(4), 391-400.

[85] Hayashi N., Molten flow behavior of soy protein isolate with low and intermediate moisture levels, J. Jpn. Soc. Food Sci., 1997, 44(3), 177-185.

[86] Holdsworth S.D., Applicability of rheological models to the interpretation of flow and processing behaviour of fluid food products, J. Texture Stud., 1971, 2(4), 393-418.

[87] Ptaszek P., Large Amplitude Oscillatory Shear (LAOS) Measurement and Fourier-Transform Rheology: Application to Food. In: Ahmed J., Ptaszek P., Basu S. (Eds.), Advances in food rheology and its applications, Woodhead Publishing series in food science, technology and nutrition, Amsterdam, Boston, Heidelberg and 9 further: Woodhead Publishing Elsevier, 2017, 87-123.

[88] Mermet-Guyennet M.R.B., Gianfelice de Castro J., Habibi M., Martzel N., Denn M.M., d. Bonn, LAOS: The strain softening/strain hardening paradox, J. Rheol., 2015, 59(1), 21-32.

[89] Heldman D.R., Lund D.B., Sabliov C., Handbook of Food Engineering, Third Edition, CRC Press, 2018. 


\section{Appendix}

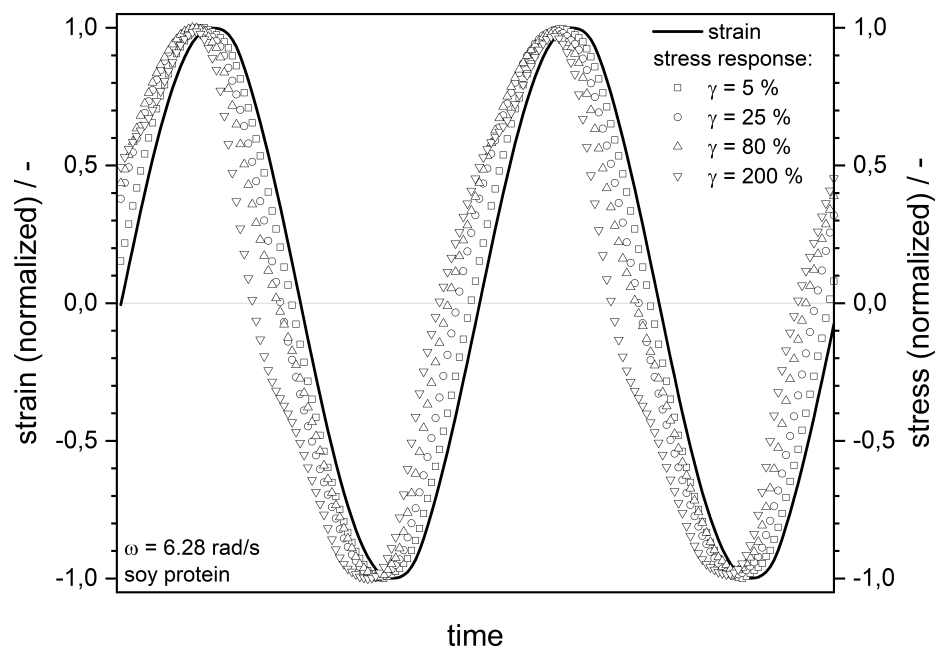

Figure A1: Excerpt of raw data of strain sweeps for soy protein, normalized strain and normalized stress plotted over time.

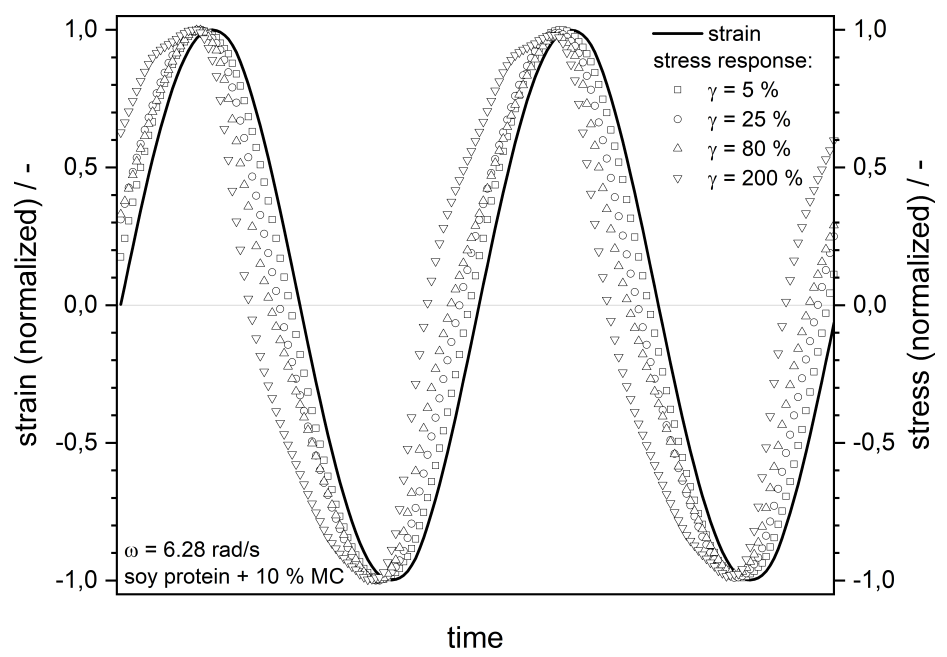

Figure A2: Excerpt of raw data of strain sweeps for soy protein $+10 \% \mathrm{MC}$, normalized strain and normalized stress plotted over time. 